\title{
Towards an Aesthetics of Reversibility or What Merleau-Ponty did not Want to Learn from Kant
}

Ingebjørg Seip

In modern art and art-criticism Kant's philosophy has been passed on as a heritage of enlightenment: To exhibit self-criticism by drawing the boundary for possible knowledge. ${ }^{1}$ In art as in philosophy these boundarydrawings tend to become projects of purification: What are the possibilities for pure experience? Paintings' acknowledgement of their own twodimensionality has been seen as the ultimate realisation of this self-reflective turn. Greenberg writes: "The tasks of self-criticism became to eliminate from the effects of each art any and every effect that might conceivably be borrowed from or by the medium of any other art. Thereby each art would be rendered 'pure', and in its 'purity' find the guarantee of its standards of quality as well as of its independence. 'Purity' means self-definition, and the enterprise of self-criticism in the art became one of self-definition with a vengeance." ${ }^{2}$

In Kant's aesthetics we may, however, see tendencies to overcome the self-referential reflection in favour of a focus on a pre-conceptual sensibility and confidence with the world. ${ }^{3}$ In the experience of beauty we feel "nature's formal finality for our cognitive faculties." ${ }^{4}$ My project in this article is to read Merleau-Ponty's philosophy of art as a radicalisation of this gesture of realism, and thus as an instance of a Kantian modernism that differs from the one outlined above by emphasising the reciprocity between man and world. Merleau-Ponty's late philosophy can be seen as an attempt to give a theoretical account of the real reciprocity behind the experience of mutual accord discussed in Kant's The Critique of Judgement. In his refusal of Kant's constitutive approach Merleau-Ponty leaves the anthropocentrism penetrating not only Kant's theoretical philosophy, but also his aesthetical reflections, where the task of aesthetic judgement is to determine the conformity of the object to the requirement of understanding. The theory of art in Merleau-Ponty's early text Phenomenology 
of Perception (1945) is still structured by this anthropological self-reflection where art is seen as a perfect mirror for the subject; art is a paradigm of the body-subject as a unity of meaning and materiality. ${ }^{5}$ In MerleauPonty's late texts Eye and Mind (1960) and The Visible and the Invisible $(V I)$ (posthumously edited 1964) this retraction of the gesture of realism is avoided: art is something we see according to ${ }^{6}$ behind the projections of man in direction of the world. ${ }^{7}$

This ontological turn may save our relation to the world, but what Merleau-Ponty is about to lose sight of is the self-reflexive focus. The investigation of sensibility towards the world itself becomes a process of purification, where the contribution of the subject is what should be effaced. In The Critique of Judgement the purification of the subjective account in aesthetical experience is proclaimed only to let the experience of beauty exhibit the pure form of the subject, and even this self-enlightening self-effacement is intercepted by the dependent beauty exhibiting the ideal of beauty: the body of man. ${ }^{8}$ My suggestion is to introduce a parallel interception of the process of purification in Merleau-Ponty's theory of art. Could a reinstallation of an anthropocentric perspective in his late philosophy open his theory to the reflection on corporeal subjectivity and inter-human encounters found in contemporary art?

\section{The incarnation of subjectivity}

Phenomenology of Perception can be read as a rehearsal of Kant's critical project in Critique of Pure Reason, to overcome the dichotomy between rationalism and empirism by means of transcendental reflections. Because Merleau-Ponty discusses the problem of perception as it is experienced from one's own body the book has, however, been understood as "radical empirism." What this empirical reading loses sight of is the transformation of the concept of the transcendental offered in Phenomenology of Perception. Merleau-Ponty connects transcendentalism to our body and being-in-the-world, and claims that the synthesizing and patterning function Kant attributes to understanding operates on the perceptual level and takes place in all parts of the nervous system. ${ }^{10}$ The body is itself an intentional structure, where the simplest movements imply outlines and projections of intention. I know my body through a body image that integrates my body into relation with a "spatiality of situation"11 that includes all the projects of the organism. Consciousness, subjectivity and understanding can thus not be separated from our corporeal practice: "Consciousness is being-towards-the-thing through the intermediary of the body."12 Kant's question about the possibility of certain knowledge is 
transformed into a question about the possibility of a perceptual universality: "We must try to understand how vision can be brought into being from somewhere without being enclosed in its perspective." ${ }^{13}$ In the early philosophy of Merleau-Ponty, the lived body and the transcendental subject is one and the same.

This embodiment of subjectivity implies a historicising of the condition of experience. As a lived body, the subject is always permeated by history, imprinted by natural and social surroundings. In the lived body history and nature converge: "The use a man is to make of his body is transcendent in relation to that body as a mere biological entity ... It is impossible to superimpose on man a lower layer of behaviour which one chooses to call 'natural' followed by a manufactured cultural or spiritual world. Everything is both manufactured and natural in man".14 Through the transcendental character of one's own body the division between culture-inscribed and nature-given emerges together with the difference between the transcendental and the empirical. Factuality becomes a historically specific transcendentalia.

To articulate this factual and cultural situatedness ${ }^{15}$ of subjectivity, Merleau-Ponty compares the body-subject to a work of art: "A novel, poem, picture or musical work are individuals, that is, beings in which the expression is indistinguishable from the thing expressed, their meaning, accessible only through direct contact, ... In this sense our body is comparable to a work of art. It is a nexus of living meanings “ ${ }^{16}$ As this analogy indicates, the theory of the subject in Phenomenology of Perception is close to the hermeneutical theory of art. From Herder's theories of language through the historicism of the 19th century to the modernistic concept of form, we find reflections on the importance of the material aspects of signification. By expanding this aesthetic and cultural theory to a theory of man and relocating it in a transcendental theory about the subject, Merleau-Ponty completes the reflection on the situatedness of knowledge found in the humanistic tradition.

\section{Art as a phenomenological investigation of space}

The shift in focus from cultural objects to one's own body transforms the process of interpretation. Hermeneutics traditionally links subjectivity and understanding to language and thus sees interpretation of aesthetical objects as a linguistic operation. From the assertions that a unity of meaning and materiality is found also in the subject, it follows that understanding can not only be seen as an intellectual process, but also as a perceptual interaction. To reach what is going on between spectators and works of 
art, theories of interpretation must confront the perceptual production of signification.

Phenomenology of Perception can be read as a philosophical articulation of the new trend in modernism around the middle of the 2oth century, when the formalistic self-reflection that had been an important strategy both in art and art-theory was given a complement by investigations of our corporeal situatedness. This shift in focus is especially notable in performance-art in the 50 s and 6os, where the body of the artist becomes the material medium of the art event. ${ }^{17}$ Also trends in more traditional works of art from the 2oth century, such as dance and painting, may, however, appear in a new light from this corporeal-phenomenological point of view. The expressive use of the body in modern dance finds in this theory a suitable frame for re-thinking the scenic situation, ${ }^{18}$ and the transformation of perspective in painting appears, as I will argue, through the phenomenological approach to space as a new realism instead of as a self-referential purification of the artistic medium.

The Euclidian space, which the classical central perspective represents and Kant's transcendental argumentation gave objectivity, is by MerleauPonty recognised as a contingent and historically situated experience of space. The space we usually inhabit is not the geometrical space conceived by a thought trained by science, but a room for action experienced through the body. Things appear "as the goal of a bodily teleology, the norm of our psyco-physiological setting." ${ }^{19}$ Our own situatedness is included, so that our perspective is immediately complemented by the scene seen from another point of view. "Thus every object is a mirror of all others. When I look at the lamp on my table, I attribute to it not only the qualities visible from where I am, but also those which the chimney, the walls, the table can 'see'; but back of the lamp is nothing but the face it 'shows' to the chimney. I can therefore see an object in so far as objects form a system or a world." ${ }^{20}$ In sense-perception the world and I are an ensemble.

To understand the paintings of for example Cézanne, we must see them as articulations of this phenomenological space. Lines, forms and size in Cézanne's pictures do not represent an abstract space, but show the world as a common place for man and things. This space is more real and less subject-oriented than the space represented in central-perspective: the cup has an inside even if it is not projectable from the front: "The 'real' is that environment in which each moment is not only inseparable from the rest, but in some way synonymous with them, in which the 'aspects' are mutually significatory and absolutely equivalent." ${ }^{21}$ This phenomenological perspectivism not only emerges in works of typical modern painters, 
such as Cézanne, Picasso or Matisse, but can also be seen in social-realistic pictures, for example by Kaare Espolin Johnson. In Juksafiskere (1955) the boats are too small and the movements of the arms too large because this is how it feels to be in a boat out on the open sea. This experience of rowing a boat is what the picture communicates to the viewer. ${ }^{22}$ Works of art are prolonging complex corporeal experiences and appear as new sense organs in both the artist and the recipient. ${ }^{23}$ As an extension and application of Merleau-Ponty's phenomenological investigation, we may, in analogy to Kant's understanding of space as an empirical reality shaped according to "the constitution of our sensibility," ${ }^{24}$ develop a concept of phenomenological realism to articulate this depicting of visual perception as an integrated part of our being-in-the world. ${ }^{25}$

Phenomenology of Perception offers a fruitful approach to tendencies in modern art and sets interpretation free from the Kantian prioritising of form and the hermeneutical prioritising of intellectual understanding. Kant's model of the subject as a unity constituting its surroundings is, however, retained, even if the subject now is understood as an empirical body. We are addressing and constituting the world through an "intentional arc which brings about the unity of the senses, of intelligence, of sensibility and motility." ${ }^{26}$ Art and man are both individual unities constituting meaning. Later Merleau-Ponty himself claims that from this model of subjective constitution the complexity of exchanges between art, world and man is not to be seen. In Phenomenology of Perception he could not solve the problem of a perceptual universality because he started from the distinction between consciousness and object. ${ }^{27}$

\section{Man as a system of intertwining}

In Merleau-Ponty's late philosophy the transformation of the transcendental strategy of argumentation is more radical. In Phenomenology of Perception the systems of exchanges and mirroring between subject and world indicates that we as subjects are always situated. In The Visible and the Invisible subjectivity is seen instead as emerging from the systems of exchanges. Robert Burch claims Merleau-Ponty “subvert the transcendental problem at its root by not admitting the dualist aporia that animates it." ${ }^{28}$ From one perspective Merleau-Ponty is in a similar situation to Kant after his theoretical critiques: He has established a new structure to conceptualise the relationship between man and world, but he has not shown how man and world come to exist for each other. Analogous to how Kant in The Critique of Judgement discusses the principle of finality as a principle "without which understanding could feel itself at home in nature," 
Merleau-Ponty explores the confidence between body and world. Kant complements the model of constitution by a regulative idea of mutual accord, and Merleau-Ponty substitutes the topic of the intentional arc with a model of reversibility between man and world. For both philosophers, the pre-objective focus moves philosophy towards aesthetics. In Eye and Mind painting is said to perform the "phenomenology of perception" that in his earlier text was executed as a theoretical investigation of psychology. "The entire history of painting in the modern period, with its efforts to detach itself from illusionism and acquire its own dimensions, has a metaphysical significance." ${ }^{30}$

It is easy to recognise the parallels between these two strategies and read Merleau-Ponty's late philosophy as a comment on Kant's concept the beautiful. In the experience of the beautiful object our cognitive faculties are brought into a free play since the world offers the imagination a form suitable for the requirement of understanding. ${ }^{31}$ Beauties of art and nature thus become paradigmatic examples of the possibility of experience. The idea of finality of nature is held, however, as a regulative a priori concept only concerning our subjective approaches and not ascribed to the world. ${ }^{32}$ We cannot give a theoretical account of it; only experience the teleology in the beauty of nature: "How is it possible to assume that nature is a complex of objects of taste? ... But the correctness of this assumption may still be seriously questioned, while the actual existence of beauties of nature is patent to experience." ${ }^{\prime 3}$ Merleau-Ponty's approach can as I have claimed be seen as an attempt to establish the aesthetic experience of mutual accord as factual, concerning our real encounters with the world. He uses the aesthetic reflection to undermine the constitutive argumentation and build up a different kind of theory to explain the experience of mutual accord.

This theory of a pre-objective accord is connected to Merleau-Ponty's earlier contention about subjectivity and perception. In Phenomenology of Perception he claims that our subjectivity is itself corporeal, and that we presuppose in our experience that objects see each other, so that my vision is complemented by the reciprocal mirroring of the surroundings. Merleau-Ponty now draws a more radical conclusion from these insights, and asserts that subject and object are of the same kind. "Between the exploration and what it will teach me, between my movements and what I touch, there must exist some relationship by principle, some kinship." ${ }^{34}$ This means that the rest of the dichotomic structure that still occurs in Phenomenology of Perception is rejected. The perceiver and the perceived is "on the same map," ${ }^{35}$ they are "as the obverse and the reverse, or again, 
as two segments of one sole circular course." ${ }^{36}$ He thus leaves the Kantian anthropocentrism that follows from the transcendental structure of argumentation in Phenomenology of Perception, in favour of a kind of objectivistic anthropomorphism. ${ }^{37}$ Instead of describing lived experience, the world as it is seen form the perspective of man, as he did in Phenomenology of Perception, he tries to describe visibility itself, or "the world of visible things;"38 a sensible world including both man and objects.

From this anti-subjectivist perspective, to perceive is to interact in a reversible field of exchanges between one's own body and the body of the world. "This can happen only if my hand, while it is felt from within, is also accessible from without, itself tangible, for my other hand, for example, if it takes its place among the things it touches, it is in a sense one of them, open finally upon a tangible being of which it is a part." ${ }^{39}$ In Phenomenology of Perception the example of the touching of the touching hand is used to show the principal difference between subjectivity and the object. Now the same example is used to exhibit subjectivity as an intern-worldly event. While Kant bound the implications of the experience of reciprocity by connecting it to a regulative a priori judgement, and in this way is able to keep the anthropocentric perspective also in aesthetics, Merleau-Ponty transforms the aesthetical experience of mutual accord into an ontological principle, a "teleology transcending the human", as Smith calls it, ${ }^{40}$ and postulates reversibility as "ultimate truth." ${ }^{\prime 1}$ To be a subject is no longer to pattern the world through our corporeal intentions, but to let oneself participate in a complex structure of reversible intertwining. The synthesis, which both for Kant and the early Merleau-Ponty is the responsibility of the subject, occurs from mutual reversibility both between our different senses, and between the senses and the sentient. We experience our body as a perceptual unit where our different senses are exchangeable with each other and expect to be able to see what we can touch and touch what we see. This perceptual self-unity - it is me who touches, sees and hears - is an aspect of the unity of the object, which is given as the same thing through all my different senses, just like the synthetic and analytical unity coincide in Kant's philosophy: "To know anything in space (for instance, a line)," Kant writes, "I must draw it, and thus synthetically bring into being a determinate combination of the given manifold, so that the unity of this act is at the same time the unity of consciousness (as in the concept of a line); and it is through this unity of consciousness that the object (a determinate space) is first known." ${ }^{\prime 2}$ For Merleau-Ponty, however, this merging of subject and object is seen no longer as a transcendental structure, but as something accessible through phenomenological description. 
Perception is understood as a circle or intertwining going on in the world, constituting both the subject and the object; "a relation of the visible with itself that traverses me and constitutes me as a seer, this circle which I do not form, which forms me, this coiling over the visible upon the visible."43 Man is an instance of a general system of intertwining. To be a subject means to be the place where the exchanges can happen: "A human body is present when, between the seer and the visible, between touching and touched, between one eye and the other, between hand and hand a kind of crossover occurs." ${ }^{44}$

\section{The flesh}

The universality of intertwining implies that exchanges also occur independent of our subjective projects. All things are reversible in relation to each other, by exchanging light, nutrition, warmth and movements. What we ordinarily call properties is actually interaction between things, a kind of self-sensation of the world. A red thing is never purely red in itself, but gains its redness from light received from other coloured things. "All flesh, even that of the world, radiates beyond itself," ${ }^{\prime 5}$ Merleau-Ponty writes. The intentional arc from Phenomenology of Perception is in The Visible and the Invisible attributed to the world itself.

Flesh is Merleau-Ponty's concept for the common mode of being that transgresses the opposition between subject and object, perceiver and perceived. Crossing the borders between materiality and spirituality, it reminds us that man should no longer be seen as the agent of synthesis, holding a multiplicity together, and the world should no longer be seen as a static collection of things. Both are parts of a "system of exchanges." ${ }^{46}$ Nature does not have to appear as organised form for our understanding to feel at home. We are at home in nature because we are a part of it ourselves, physical bodies participating in the exchanges and structures of reversibility. This participation makes it possible for us to experience and comprehend the manifold as manifold - as a complex and always transforming structure - and not only, as Kant claimed, understand the cases where the imagination offers us a clear form corresponding to the form of a concept. Because the pre-objective universality, flesh, is the point of origin both of facticity and significance, the reconciliation is always already carried out. Flesh is concrete and particular - and thus facticity but because the concrete thing is always a special kind of thing, it is also meaning: "The inauguration of the where and when, the possibility and exigency for the fact; in a word, facticity, what makes the fact be a fact. And, at the same time, what makes the fact have meaning, makes the frag- 
mentary facts dispose themselves about 'something'." ${ }^{47}$ Particulars' being something results from the exchanges between things, as colours result from exchanges of light. The things participate in a connection of significance by being lined with a "fabric of invisible being." ${ }^{48}$

\section{A vision in general}

The system of intertwining offers a solution to the principal problem from Phenomenology of Perception, "how vision can be brought into being from somewhere without being enclosed in its perspective." ${ }^{\prime 49}$ If subjectivity is the place where intertwining and reciprocity occur, it becomes something we share, something oscillating between us, not a private property fixated to each of us separately. Because universality is established already on the perceptual level the classical problem of solipsism does not arise. The Kantian universal reason is transformed to a universal visibility where perception is an event in "an intercorporeal being"50.

There is here no problem of the alter ego because it is not $I$ who see, not he who sees, but an anonymous visibility inhabits both of us, a vision in general, in virtue of that primordial property that belongs to the flesh, being here and now, of radiating everywhere and for ever, being an individual, of being also a dimension and a universal..$^{51}$

If we follow Merleau-Ponty's suggestion and turn to art to understand metaphysics, we may view AK Dolven's film between two mornings ${ }^{52}$ as a direction of this universal perceptibility. Imagine an uncut, four minute long film showing four naked bodies on a beach, looking at the sea. Their arms are invisible and their skulls clean-shaven. There is no sound except the ticking of the spool. Nothing happens except the nearly imperceptible changes of light and the small waves coming towards the spectators as an endless repetition. Through a reciprocal play between light, space and time a perceptual reversibility is performed. Visibility comes from everywhere through an all-embracing mirror-structure, where light and darkness are exchanged between the elements. The four figures on the beach multiply the perspective, but because of the spread of light and the extension of the landscape they divide point of view. Their visions are at rest at the same point, even if their gazes are parallel. We are given a depth without central perspective, a time without direction, a mutual perception without a shared place to see from or a common object to look at. Perception is produced as a structure of intertwining and exchange. The audience enters as viewers at the back row: the experience of art is directed as a sharing of perceptual field. 
Ingebjørg Seip

Images removed

due to copyright

Kaare Espolin Johnson, Juksafiskere. 1955. ๑ Gisle Espolin Johnson/в оNо.

AK Dolven, between two mornings. $35 \mathrm{~mm}$ film, 2004. 


\section{The effacement of differences}

Merleau-Ponty has been criticised for ending in a monistic philosophy à la Schelling, where the difference between I and world dissolves in an all-embracing anthropomorphism: "there is no essential otherness nor real development within Being", ${ }^{53}$ claims Robert Burch. The community of anonymous visibility immediately reproduces the solipsism it should efface. "The subtlety of what is said of the visible and its relation to the flesh does not rule out the solipsistic character of this touch(ing) between the world and the subject, of this touch(ing) of the visible and the seer in the subject itself", ${ }^{4}$ Luce Irigaray sighs. If every exchange is to be seen as reversible, all differences will disappear. "All that remains to be said is that the world is isomorphic with the subject and vice versa, and the whole is sealed up in a circle. Nothing new happens, only this permanent weaving between the world and the subject." ${ }^{n 5}$

The critique by Luce Irigaray is interesting from our perspective, because she points to the connection between the effacing of the border between man and world and a dissolving of the differentiation in the subject, as differentiation of our senses, and between the subjects, as the willingness to see the other as a different other. Like the un-individuated bodies in between two mornings we are sitting on a beach seeing the waves brake: "We never catch sight of each other, and we do not see each other's eyes." ${ }^{56}$

\section{The utopia of reversibility and the question of style}

Merleau-Ponty, however, is attentive to the danger of monism. By postulating an immanent fission or abyss in the concept of reversibility he admits the necessity of an opening towards differentiation. The circular relations between us and the world are possible "by virtue of the fundamental fission or segregation of the sentiment and the sensible. ${ }^{57}$ For exchanges to be possible there have to be differences to be reversed. Because every exchange creates new openings, differentiation and segregation happen in the same moment reversibility is displayed, so that reversion can never be completed. All experience thus implies an element of incompleteness, it is always something that exceeds integration. The concept intentional arc from Phenomenology of Perception attributes this capacity to exceed to the subject. In his later texts the transgression is situated on both sides of the I-world relation, and appears as interceptions or postponements of the postulated exchanges. As an echo of the regulative character of Kant's principle of finality of nature, reversibility appears as "always imminent and never realized in fact." ${ }^{58}$ 
This postponement of the realisation of a factual reversibility settles as interceptions and displacements in the argumentative structure, where no statements could be taken as immutable proposition. Also the insight in the postponement is postponed. In the essay "Intertwining - The Chiasm" this is striking. Through a structure of slippages and explicated displacements the reversibility postulated at the beginning is recognised as a utopia towards the end. The quotation above begins: "To begin with, we spoke summarily of a reversibility of the seeing and the visible, of the touching and the touched. It is time to emphasize that it is a reversibility always imminent." ${ }^{\prime 59}$ The textual web not only performs reversibility of experience by offering the argument in a literary and sensual style, also the limitations of the exchanges are performed. This is necessary because the limitations are not understood as a transcendental a priori border, but a factual delay we experience in the world. Again Merleau-Ponty looks down at his hands: "My left hand is always on the verge of touching my right hand touching things, but I never reach coincidence; the coincidence eclipse at the moment of realization." 60

In Irigaray's critique of Merleau-Ponty the main point is, as mentioned, that the difference of the other emerges together with the difference between man and world. The structure of fissions and segregations seems, at first sight, to open our experiences to the exisistence of the other. Because I could not accomplish the exchanges myself, I need the gaze of the other as a necessary complement to mine. The other must complete the blind spots in my field of vision for the world to be whole; we must rely on each other for the openings to close. In Phenomenology of Perception this necessary view from the outside was attributed to the chimney, the walls and the tables. In this withdrawal of the ontologisation of reversibility the supplementary view is recognised as the gaze of the other. Analogous to Kant who postulates Sensus Communis as "a necessary condition of the universal communicability of our understanding," ${ }^{\prime 1}$ and claims that we must assume that our cognitive faculties are similar in all of us, MerleauPonty recognises the perception of the other as a condition for both our perception of the world and our self-perception: "As soon as I see, it is necessary that the vision ... be doubled by a complementary vision or with another vision: myself seen from without." ${ }^{2}$

The theory of the other as a necessary supplement is, however, soon extended to a theory of the other as an aspect of a generalised perceptibility. My different senses give me one experience of one thing, and are thus reversible. Why should I not be able to extend this experience of synergy and exchange to include the perception of the other? "Why would not the 
synergy exist among different organisms, if it is possible within each? Their landscapes interweave, their actions and their passions fit together exactly." ${ }^{63}$ To enter into a perceptual universality is to assume that the perceptions of the other are or could have been reversible with mine. Merleau-Ponty claims that this mutual reversibility could be possible only if the idea of a unity of consciousness is abandoned and the differentiations between me and the other are effaced: "This is possible as soon as we no longer make belongingness to one same 'consciousness' the primordial definition of sensibility, and as soon as we rather understand it as the return of the visible upon itself, a carnal adherence of the sentient to the sensed and of the sensed to the sentient." ${ }^{64}$ In this open field of perceptibility Narcissus meets another Narcissus in an "intercorporeity." ${ }^{\prime 5}$ There is no hymen between my hand and the hand of the other. "[W]hy, when touching the hand of the other, would I not touch in it the same power to espouse the things that I have touched in my own?"66 The experience of the other as an experience of a different view is immediately transformed into an experience of "a vision in general." ${ }^{67}$ Merleau-Ponty substitutes the regulative demand for agreement in judgements by a model of open complementarity. Kant's regulative demand is, however, always confronted with the disagreements of empirical subjects. This is why taste needs cultural education. ${ }^{6}$ When universality is to be displayed in the empirical field of the world, there seem to be no places for individuality and differences to hide; if not art may give us a hint?

\section{Art as experience of the worlds looking back}

As Kant, Merleau-Ponty turns to art, especially to painting, for investigation of our relation to nature and to each other. Painting is seen as a corporeal metaphysic, ${ }^{69}$ a manual praxis that investigates the reversibility in the world. While philosophy can only imitate the exchanges through the linguistic web, art can exhibit both the exchanges and their borders and with this demonstrate how the world is given as something different from us. Merleau-Ponty insists that art is neither a mirror for man's cognitive faculties nor a representation of the world, but something that lets the world speak: "No longer is it a matter of speaking about space and light, but of making space and light, which is there, speak to us." ${ }^{70}$ The painter is animated by a philosophy that lets vision "reassume its fundamental power of manifestation, of showing more than itself." ${ }^{\prime 1}$ He exhibits a corporeal metaphysic by working through the reversible interplays between hand and eye, tactility and visuality. "Indeed we cannot imagine how a mind could paint," Merleau-Ponty writes. "It is by lending his body to the 
world the artist changes the world into paintings."72 Works of art, as man, are seen as places where the exchanges happen. By a rehearsal of the multiple works of crossing and exchanging every perception implies, they exhibit the factuality of the processes of exchanging, and thereby the reality of the world. "A painter cannot agree that our openness to the world is illusory or indirect, that what we see is not the world itself, or that the mind has to do only with its thoughts or another mind."73 The movements of the hand come into being in interplay with something outside the body. Merleau-Ponty replaces the metaphor of re-production with a metaphor of encounters; to be able to paint is to let oneself be penetrated by the radiation of the world. He quotes Klee: "the trees were looking at me, were speaking to me ... I was there, listening ... I think that the painter must be penetrated by the universe and not want to penetrate it." ${ }^{\prime 74}$ To paint is to recreate the world as a power of sight, the world's gaze back. This is why art is "the voice of the light."75 It produces signification, not by being a subjective projection, but because it participates in the real plays of exchanges in the real world, where all signification is produced.

Painting thus shows us the world without representing it. The painter works through the exchanges in the world, the continuous play of light, structures and colours, to establish colours, perspective and depth in the picture. To paint a colour and a form, you always have to use other colours and project the form in a way not objectively given. For the grass to look green you must add red. For the line to look straight, it must be a bit lopsided. If a painting is going to grasp the world, it must play through the plays in and between colours and forms, which means that it must explore its own design, be auto-reflexive. Through exploring how colours and lines influence each other on the canvas, the painter shows the reversibility of the world, how colour, light, movements, warmth and nutrition continuously exchange. This means that a painting must be auto-figurative to be figurative: "Ultimately the painting relates to nothing at all among the experienced things unless it is first of all 'autofigurative'"m6 it can only represent something by "being a 'spectacle of nothing', by breaking the 'skin of things' to show how the things become things and how world become world." ${ }^{77}$ As auto-reflection, painting explores the auto-reflection of the world.

The work of art thus participates in the intertwining and exchanges of the world, and to be a spectator is to participate in this participation, to look through or together with the picture, not to look at it. Works of art offer us a sharing of perceptual mood that open us onto the meaning of the world: "Rather than seeing it, I see according to, or with it." 78 This 
invitation to share addresses us as bodies in the world, because it is as bodies we are able to participate in the exchanges: "[I]t does not offer the mind an occasion to rethink the constitutive relations of things, but rather it offers the gaze traces of vision, from the inside, in order that it may espouse them; it gives vision that which clothes it within, the imaginary texture of the real." ${ }^{79}$ Through painting we get access to bodily encounters in the world.

\section{Art as self-portrait}

The experience of art thus seems to save the world as an other for the viewer, but the body of the other still remains to be investigated. If we look closer at Merleau-Ponty's critique of art, we will see that what he focuses on is the artist's gaze onto the world, the same gaze investigated in between two mornings. The gaze of the artist is like "the 'round eye of the mirror"' a "prehuman way of seeing things." ${ }^{80}$ As a mirror, painting displays how the world comes into being for us: The painter asks the mountains to "unveil the means, visible and not otherwise, by which it makes itself mountain before our eyes." ${ }^{\prime 1}$ This is the same project Merleau-Ponty attributes to philosophy: "It is the things themselves, from the dept of their silence, that (it) /philosophy/ wishes to bring to expression." ${ }^{22}$ The subject-object dichotomy from Phenomenology of Perception is left behind, but the problem is still the encounter with the world.

Painting, however, also shows man as a part of the world. As art displays an encounter with the forest and the mountains, it can display an encounter with the other: "The mirror's phantom draws my flesh into the outer world, and at the same time the invisible of my body can invest its psychic energy in the other bodies I see. Hence my body can include elements drawn from the body of another, just as my substance passes into them; man is a mirror for man. Mirrors are instruments for a universal magic that converts things into spectacle, spectacle into things, myself into another, and another into myself." ${ }^{n 3}$ Here the other seems to be found through the mirror of art.

Merleau-Ponty does not, however, ask for the difference between our encounters with the world and encounters with each other. He writes about the living smile on the canvas, and gives Cézanne's painting Mont. Saint-Victoire as an example. He writes about Cezanne's landscapes, Klee's leaves of holly and how paintings present objects. Even when he discusses Matisse's drawings of women, he uses them as examples of how we see and paint things; "to constitute it as nude, as face as flower." ${ }^{84}$ This displacement of perspective is not due to an unconscious slippage, but 
is a consequence of Merleau-Ponty's understanding of the nature of the perceptual fellowship. We get access to the other only through participation in a common world: "But at the very moment that I think I share the life of another, I am rejoining it only in its ends, its exterior poles. ... it is the thing itself that opens unto me the accesses to the private world of another." ${ }^{85}$ The parallel view is producing the fellowship: "we are two witnesses capable of hovering over the same true object." ${ }^{\prime 16}$ The consequence is that not only the difference between man and thing, but also the difference between the other and me avoids attention. The self-portrait becomes the paradigm of the encounter, embodying both sides of the vision in the same all-embracing visibility we have already seen in between two mornings. The painters paint themselves "as if to attest to there being a total or absolute vision, leaving nothing outside, including themselves." ${ }^{17}$ In the process of saying the world Merleau-Ponty's theory of perceptual intertwining does seem to efface the other as other.

In the discussion of art-criticism in relation to Phenomenology of Perception I used the concept phenomenological realism to articulate how the perceptual field is shaped by movements and corporeal interaction and showed how this phenomenological space could be seen as the space displayed in modern art. As a consequence of the shift in focus from the corporeal aspect of subjectivity to the reciprocal exchanges, the question of space and movement is transformed in Merleau-Ponty's late philosophy. He no longer discusses the corporeal experience of movement in one's own body, but how movements appears from the outside. Seen from the outside movements raise the problem of the relation between time and space. "Movement is given, says Rodin, by an image in which the arms, the legs, the trunk, and the head are taken at a different instant, an image which therefore portraits the body in an attitude which it never at any instant really held." ${ }^{\prime 8}$ Merleau-Ponty's examples are Géricault's paintings of horses. What produces realism from this perspective is the temporalization of the gaze through a projection of time into space, not the depiction of space as it is experienced as a field for our own movements. "It is the artist who is truthful, while the photograph lies, for, in reality, time never stops." ${ }^{89}$ For Merleau-Ponty Géricault's paintings do not represent how it feels to ride, but how it feels to view a rider. The distance to the problem of movements displayed in the pictures of Espolin Johnson is striking. Movements are no longer understood as constitutive elements in the gaze viewing, as a knowledge of how to row a boat or walk up a mountain, but are sought for in the movements of the paint brush and in the object depicted. 
In the film by AK Dolven the distant and parallel view appears as a commentary to the modern experience of loss of practical fellowship. The absence of manual forms of praxis settles in perception as a passive loneliness and a naturalization of the cultural and technical arrangements. Stripped of all individuality and tools for communication and action hair, hands, legs, mouths, eyes - the bodies appear as nature. The women blend in like stones on the beach just like the contents of the beauty-bag appear as shells in the sand. The audience of the film doubles the contemplating situation, sitting unmoving in the dark. In a culturally constructed event we are all alone together against the sea, waiting. As a critical objection the film is a commentary to the modern paralyses of the subject. In Merleau-Ponty's anti-anthropocentric philosophy these self-referential and critical elements are lacking, and the alienation is not recognised. The subordination of the encounter with the other under our encounter with the world therefore appears as an ontological condition. Through his discussion of perception and the worlds gaze back, his late philosophy gives us a fruitful theoretical articulation of how the relation between man and world is displayed in modern art. He draws however, in his eager to purify experience from the subjective account, attention away from investigations of physical self-reflection and corporeal intersubjectity in arts, aspects displayed by the subject-oriented theory in Phenomenology of Perception. In many projects of contemporary art this bodily contribution is the essential part, as seen for example in art-projects by Ann Hamilton, Janie Antonio or Kirsten Justesen. ${ }^{90}$

\section{The impure beauty and the contribution of the subject}

In Kant's aesthetics the withdrawing of the purification of the subjective account allows man's corporeal self-reflection in art to be seen. The Critique of Judgement tells us that only where we are able to disregard the theoretical and practical interests of the subject may we experience a pure beauty. The pure beauty should be something outside man's constitutive field, and the perceiving subject stands on the border trying to experience the world independent of his own imprints. This border is, however, impossible for Kant to draw, as Jacques Derrida has shown. ${ }^{91}$ Neither is it possible to arrange the examples into the classifications of the theory, nor is the pure beauty sufficiently fixated to be the ideal of beauty. In Kant's retraction of the demand for purity he claims that the aesthetic experience of finality of form is most clear in man's confrontation with representations of man, because the arrangement of the manifold here is related to an internal finality. A statue or a portrait exhibits a thing in the 
world that itself "is able to determine his ends by reason." ${ }^{\text {" T2 }}$ The subjective demand for finality is present both in viewer and the viewed. The contribution of the subject is thus reflected and redoubled instead of effaced. Anthropocentrism is reintroduced at the moment it seems to have been overcome.

If we return to Merleau-Ponty's late philosophy looking for an equivalent self-referential focus of man, we do not find an encounter with the other through art, but an encounter with the other as if he was a work of art, a strange statue. The reciprocal touching between man and man as art is the beginning of expression: "For the first time, the body no longer couples itself up with the world, it clasps another body, applying itself to it carefully with its whole extension, forming tirelessly with its hands the strange statue which in its turn gives everything it receives ... And henceforth movement, touch, vision, applying themselves to the other and to themselves, return towards their source and, in the patient silent labour of desire, begin the paradox of expression." ${ }^{\prime 93}$ The touch of the other is the origin of language. It seems, however, to be a secondary experience, a for the first time, after the coupling with the world.

My question to the text is whether the use of metaphors may be turned around, so that our meetings with a real statue can be seen as something exhibiting the paradox of expression. If we, as Merleau-Ponty does, see art as a perceptual investigation of the perceptual interplays that make signification possible, should not the encounter with the picture of another body display the production of meaning in a more significant way than an encounter with a picture of nature? What happens if we ask how the experience of the touching hand is understood in confrontation with a portrait of a man touching his left hand with his right? May a focus on the ideal of beauty, the human shape, unveil the impure of Merleau-Ponty's late philosophy: The contribution of the subject?

If the impure beauty is to be pursued, the concept phenomenological realism from our reading of Phenomenology of Perception gives us an interesting approach. In the phenomenological realism, the impure, the contribution of the subject, is what is exhibited in art. The picture of the other shows us the world imprinted by a bodily teleology, and through a corporeal reading of the picture may we experience the experiences of the other. However, also the insights articulated in Merleau-Ponty's later texts must be examined. Only a model where the interaction between man and world is seen as a mutual structure of reversibility can explain how works of art may point beyond themselves, towards the world. Through a critical use of Merleau-Ponty's late philosophy we can learn to include the subjective 
element without isolating it as constitutive factor. My suggestion is that the concept of reciprocity is awarded with an anthropocentric turn, so that it is our own position in the play of exchanges we focus on. Then the experience of art may show us the contribution of the subject, neither as a constitutive transcendental structure, nor as the one part of a chiasm between man and world, but as a factual sensus communis, a community of perception. If we perceive according to a picture, created by man, exhibiting man through the exchanges between material factors, we may experience that interchanges with the other opens our relation to the world. The parallel perception turns up as secondary. Does not the touch of the other occur before our hand touches the world?

\section{The reversibility of sensations}

Let us again turn to art to see how the encounter with the other can be staged. The installation Homo sapiens sapiens ${ }^{94}$ by Pipilotti Rist is interesting as an example, because it displays our perceptions of the physical world as something that happens between us, and stages the other as a mirror that allows sharing of perceptions and feelings. The event occurs in a church no longer in use. As viewer, you step over a communion rail and lie down on a mattress on the floor. Looking at the ceiling, you experience pictures mirroring each other. You see bodies perceiving, touching and moving around in a landscape of leaves and plants. What happens is that you become part of the installation, and you recognize that your body is a mirror through which you can meet the other and perceive the other's movements, pleasures and touches. You feel the guava in your own hand and the grass on your face. You sense their sensations in your own body. Homo sapiens sapiens shows us an alternative to the parallel view; shows us what will happen if we catch sight of each other. We experience that the feeling of perception is directly sharable through a mirroring structure between our bodies. Not only light, but also subjectivity is exchangeable and reversible. Through this reversibility of life between us and the pictures above our heads, we experience what it is like to be the other. Pipilotti Rist has produced an alternative to the lonely, modernistic, parallel gaze against an unlimited horizon, and taken the empty house of God back as a house of man.

Merleau-Ponty has given us all the concepts we need to articulate this event of encounters, but tends to efface what he exhibits, subordinating everything to a generalised reversibility that does not distinguish between man and things. If we annul the banishment of the subjective account, we may get both a new understanding of man's contribution to experience 
Ingebjørg Seip

\section{Images removed \\ due to copyright}

Pipilotti Rist, Homo sapiens sapiens. Audio video installation (video still), Courtesy of the artist and Hauser \& Wirth Zürich London, 2005. 
and a new access to art. Work of art appears not only to be our other, an other standing beside us, a common being we can look at the world together with, but also to be our other by turning towards us. Perhaps the secret of art is its ability to conserve and emit some of the mirroring magic we experience in the relation to other people? To view a portrait of man gives us the feeling of being looked at, being touched, being moved by the other's sensations. It thus shows us humanity as the ability to perform a reversibility of sensations and feelings, to let oneself be moved by the other. Art produces the exchanges between differences that theory struggles to give an account of.

The experience of empathy and identification with the stranger has bewitched lovers of art from all social classes throughout the ages, but has been an absolute taboo for modern art-criticisms. Only an aesthetic that dares to re-think the emotional and corporeal relations between us and art, may release art-reception and help us understand why art is still important in our lives. Reflection of the intercorporeal circulation of subjectivity is especially necessary to understand art that works with intercorporeal meetings, just as this work by Pipilotti Rist. The philosophy of Merleau-Ponty has opened the field and given us some fruitful concepts, and Kant has reminded us of the requirement of a recollection of our own subjectivity. The work to be done is to investigate the production of subjectivity in the perceptual exchanges between us through an investigation of our encounters with art. Kant taught us that the correctness of this assumption of mutual accord may still be seriously questioned, while the actual existence of contemporary art is patient to experience. ${ }^{95}$

\section{Notes}

1. Clement Greenberg is, as we know, the most prominent representative for this understanding of the connections between Kant and modernism: "I identify Modernism with the intensification, almost the exacerbation, of this self-critical tendency that began with Kant. Because he was the first to criticize the means itself of criticism, I conceive of Kant as the first real Modernism." Clement Greenberg, "Modernist painting," in Art in theory 1900-2000, ed. Charles Harrison and Paul Wood (Malden, Mass: Blackwell Publishing, 2003), 774.

2. Ibid., 775 .

3. See e.g. Hjørdis Nerheim, Estetisk rasjonalitet. Konstitusjonsbegrepet i Kants "Kritikk der Urteilskraft" (Oslo: Solum Forlag 1991).

4. Immanuel Kant, The Critique of Judgement, James Greed Meredith, trans. (Oxford: Clarendon Press, 1957, reprint 1986), 35. 
Ingebjørg Seip

5. Maurice Merleau-Ponty, Phenomenology of Perception, Colin Smith, trans. (London: Routledge Classics, 2006), 175.

6. Maurice Merleau-Ponty, "Eye and Mind," in The Merleau-Ponty Aesthetics Reader. Philosophy and Painting, ed. Galen A. Johnson, Michael B. Smith, trans., (Evanston, Illinois: Northwesten University Press, Studies in Phenomenology and Existential Philosophy, 1993), 126.

7. Michael B. Smith writes: "Painting is no longer an anthropocentric function, and Being is now capitalized. The human being, through whom Being expresses itself, is the privileged locus in which the world turns back upon itself, becomes a 'visible seer."' Michael B. Smith, "Merleau-Ponty's Aesthetics", in The MerleauPonty Aesthetics Reader. Philosophy and Painting, ed. Galen A. Johnson, Michael B. Smith, trans. (Evanston, Illinois: Northwesten University Press, Studies in Phenomenology and Existential Philosophy, 1993), 206.

8. Kant, op.cit., 76 .

9. Smith, op.cit., 194.

10. Merleau-Ponty, Phenomenology of Perception, 87.

11. Ibid., 114-115.

12. Ibid., 160.

13. Ibid., 78.

14. Ibid., 220.

15. Ibid., 294: "being is synonymous with being situated."

16. Ibid., 175 .

17. See e.g. Erika Fischer-Lichte, "Performance art and ritual: bodies in performance," in Performance. Critical concepts in literary and cultural studies, Volume IV, ed. Philip Auslander (London and New York: Routledge 2003), 228-251: 243ff.

18. See p.g. Sondra Fraleigh, Dance and the lived Body (Pittsburgh: University of Pittsburgh Press, 1987).

19. Merleau-Ponty, op.cit. 376.

2o. Ibid., 79 .

21. Ibid., 376.

22. In later versions this effects is even stronger, especially in the versions from 1978 and 1985, where space is totally subordinated to the corporeal movements.

23. Merleau-Ponty, op.cit., 212.

24. Immanuel Kant, Critique of Pure Reason, Norman Kemp Smith, trans. (London: Macmillan, 1993), B44.

25. For a discussion of Merleau-Ponty and the concept phenomenological realism see Ingebjørg Seip, "Å se med kroppen. Fiksjon og fenomenologisk realisme hos Espolin Johnsen og AK Dolven," in Vaa, Aaslaug: Å låne øyne å se med. Kaare Espolin Johnsons kunstnerskap (Trondhein: Tapir Akademisk forlag, 2007), 202-237. 26 Merleau-Ponty, op.cit., 157. 
27. See Remy C. Kwant, From Phenomenology to Metaphysics (Pittsburgh: Duquesne University Press, 1966), 38.

28. Robert Burch, "On the Topic of Art and truth," in The Merleau-Ponty Aesthetics Reader, 364.

29. Kant, The Critique of Judgement, 35.

30. Merleau-Ponty, "Eye and mind," 139.

31. Kant, op.cit., 58 .

32. Ibid., 20.

33. Ibid., 148.

34. Maurice Merleau-Ponty, The Visible and the Invisible, Alphonso Lingis, trans. (Evanston, Nortwestern University Press, 1968), 133.

35. Ibid., 133 .

36. Ibid., 138.

37. Smith, op.cit., 199: "If I have understood the meaning of Merleau-Ponty's later philosophy, it concedes to anthropomorphism its share of truth, by virtue of the fact that the ontological condition of being (as 'being -in-the-world') and the being of the world are the same."

38. Burch, op.cit., 367: "He thus gives us the essence, not of the perceived world as it is lived, that is, in its full richness of meaning as the context of my projects, but a world of visible things..."

39. Merleau-Ponty, op.cit., 133.

40. Smith, op.cit., 193.

41. Merleau-Ponty, "Eye and mind," 155.

42. Kant, op.cit., B138.

43. Merleau-Ponty, The Visible and the Invisible, 140.

44. Merleau-Ponty, "Eye and mind," 125.

45. Ibid., 145 .

46. Ibid., 125 .

47. Merleau-Ponty, The Visible and the Invisible, 140.

48. Ibid., 132.

49. Merleau-Ponty, Phenomenology of Perception, 78.

50. Merleau-Ponty, The Visible and the Invisible, 143.

51. Ibid., 142.

52. AK Dolven, between two mornings, $35 \mathrm{~mm}$ film (2004).

53. Burch, op.cit., 362.

54. Irigaray, Luce, "The Invisible of the Flesh," in The continental aesthetic reader, ed. Clive Cazeaux, Carolyn Burke and Gillian C. Gill, trans. (London and New York: Routledge 2000), 566.

55. Ibid., 581.

56. Ibid., 581. 
Ingebjørg Seip

57. Merleau-Ponty, op.cit., 143.

58. Ibid., 147.

59. Ibid., 147.

6o. Ibid., 147.

61. Kant, The Critique of Judgement, 84.

62. Merleau-Ponty, op.cit., 134.

63. Ibid., 142.

64. Ibid., 142.

65. Ibid., 141.

66. Ibid., 141.

67. Ibid., 142.

68. Kant, op.cit., 266.

69. Merleau-Ponty, "Eye and Mind," 139.

7o. Ibid., 138.

71. Ibid., 138.

72. Ibid., 123.

73. Ibid., 146.

74. Ibid., 129.

75. Ibid., 142.

76. Ibid., 141.

77. Ibid., 141.

78. Ibid., 126.

79. Ibid., 126.

8o. Ibid., 129.

81. Ibid., 128.

82. Merleau-Ponty, The Visible and the Invisible, 4.

83. Merleau-Ponty, "Eye and Mind," 129-130.

84. Ibid., 144.

85. Merleau-Ponty, The Visible and the Invisible, 11.

86. Ibid., 13.

87. Merleau-Ponty, "Eye and Mind," 130.

88. Ibid., 145.

89. Ibid., 145, after Rodin.

90. For a discussion of corporeal art and how it challenges the role of the spectator, see: Ulla Angkjær Jørgensen, Kropslig kunst. cestetik, køn, kunstanalyse (København: Museum Tusculanums Forlag, 2007).

91. Jacques Derrida, Truth in Painting, Geoff Bennington and Ian MaLeod, trans. (Chicago and London: University of Chicago press, 1987). The Sans of the pure cut, $83^{-118}$, e.g. 112 . Derrida writes as if this anthropocentrism is a surprise, something we should have seen it is not. 
Towards an Aesthetics of Reversibility

92. Kant, op.cit., 77 .

93. Merleau-Ponty, The Visible and the Invisible, 144.

94. Pipilotti Rist, Homo Sapiens sapiens. Audio video installation in San Stäe am

Canal Grande, Venezia-biennale 2005.

95. See Kant, op.cit, 148. 